\title{
Heat Transfer Measurement in a Three-Phase Direct-Contact Condenser under Flooding Conditions
}

\author{
Hameed B. Mahood ${ }^{1,2^{*}}$, A. N. Campbell ${ }^{1}$, A.O. Sharif ${ }^{1,3}$ and R. B.Thorpe ${ }^{1}$ \\ ${ }^{1}$ Centre for Osmosis Research and Applications (CORA), Chemical and Process Engineering \\ Department, Faculty of Engineering and Physical Sciences, University of Surrey, Guildford \\ GU2 7XH, UK \\ ${ }^{2}$ University of Misan, Misan-Iraq \\ *hbmahood@yahoo.com \\ ${ }^{3}$ The Qatar Foundation, Qatar Energy and Environment Research Institute, Qatar
}

\section{Abstract}

The transient temperature distribution and volumetric heat transfer coefficient during the inception of flooding in a three-phase bubble type direct contact condenser have been experimentally investigated. The flooding mechanism and the factors affecting the onset of flooding of the three-phase direct contact column are not considered. A short Perspex column of $70 \mathrm{~cm}$ total height and $4 \mathrm{~cm}$ internal diameter utilising two immiscible fluids was studied. Pentane vapour with initial temperatures of $40^{\circ} \mathrm{C}, 43.5^{\circ} \mathrm{C}$ and $47.5^{\circ} \mathrm{C}$ was the dispersed phase and tap water at a constant temperature $\left(19^{\circ} \mathrm{C}\right)$ was the continuous phase. Only $48 \mathrm{~cm}$ of the column was used as the active height and different mass flow rates of both phases were used. The experimental results showed that the instantaneous temperature distribution along the direct contact column tends to be uniform when the direct contact column is working under flooding conditions. Furthermore, the volumetric heat transfer coefficient increases as the dispersed mass flow rate is increased towards the flooding limit and remains constant along the column height. In addition, the dispersed phase mass flow rate that leads to flooding increased with increasing mass flow rate of the continuous phase. The initial temperature of the dispersed phase did not have a considerable effect on the flooding inception limit under the present experimental conditions.

Keywords: Flooding; three-phase direct contact heat exchanger; transient temperature distribution; volumetric heat transfer coefficient 


\section{Introduction}

34 Conversely, to the indirect contact heat exchange, direct contact heat exchange relates to the transportation of thermal energy between two or more fluid streams when they are brought into intimate contact with one another. Accordingly, heat exchangers can be split into two main types: classical, or surface type, and direct contact type. In the former, the two fluid streams, (hot and cold) are completely separated by a metallic or solid barrier, and heat is transformed through it. Therefore, the ability of this type of exchanger to extract the thermodynamic potential energy is constrained due the heat transfer resistance of the metallic surface, which is also exposed to fouling, corrosion and thermal stresses, especially when it used over a high temperature range.

Practically, the direct contact heat exchanger (condenser in the present case) can be split into two main types: single component direct contact condenser, when the same chimerical species is used, for example condensing of steam in water. The second type is twocomponents (or three-phase) direct contact condenser. In this type, two completely immiscible fluids are used, for example condensing of pentane vapour bubbles in subcool water.

The condensation of a vapour bubble in another immiscible liquid (i.e. a two-component system) is different from when it condenses in its own liquid (i.e. one-component system). This is because in a two-component system a confined vapour/liquid two-phase bubble is formed. Hence, the liquid condensate remains within the mother bubble, in contrast to the one-component system where the condensate mixes with the surrounding fluid. The vapour and liquid within the two-phase bubble are completely separated due to the effect of gravity. As shown in Fig. (1), vapour collects at the top of the two-phase bubble whilst liquid spreads and accumulates at the bottom with a monolayer film of condensed liquid covering the whole bubble surface $[1,2]$. Therefore, three distinct phases (pentane liquid-pentane vapour-water) are present in the process and a three-phase direct contact condenser is emerged similar the case of three-phase direct contact evaporator [3-7].

60 The three-phase, direct contact condenser, however, can be classified into to three main types

61 [8]: drops, film and bubble type direct contact condensers. Among these, the bubble type 62 three-phase condenser has a relatively high efficiency, is simple in design and construction and low in cost [9]. 
Fig. 1. Configuration of two-phase bubble condensation in an immiscible liquid (a represents the two-phase bubble radius, $\mathrm{U}$ denotes the continuous phase velocity, $V_{r}$ and $V_{\theta}$ are the radial and tangential velocity components, $\theta$ is the angle in spherical coordinate).

Generally, the three-phase bubble type direct contact condenser (Fig. 2) consists of a vertical cylindrical column and injection devices such as nozzles or plate orifices fixed at the top and bottom of the column for injection of the dispersed and the continuous phase (Fig. 2). Vapour bubbles, often a light hydrocarbon vapour, is commonly used as a dispersed phase while another immiscible liquid (usually water) as a continuous phase. The temperature of the continuous phase is maintained less the saturation temperature of the dispersed phase.

Driven by the buoyancy force, the dispersed phase (as two-phase, vapour/liquid bubbles, Fig (1)) travels up the column through the falling continuous phase and heat is absorbed by the continuous phase, which results in a portion of vapour bubbles instantaneous condensing along the column. Thus, the vapour bubbles are condensed completely in an active height, which depends on several parameters, such as temperature difference, mass flow rate ratio and the physical properties of both phases. The condensate is collected and returned to the closed cycle, while the continuous phase is drained out from the column bottom. 
93

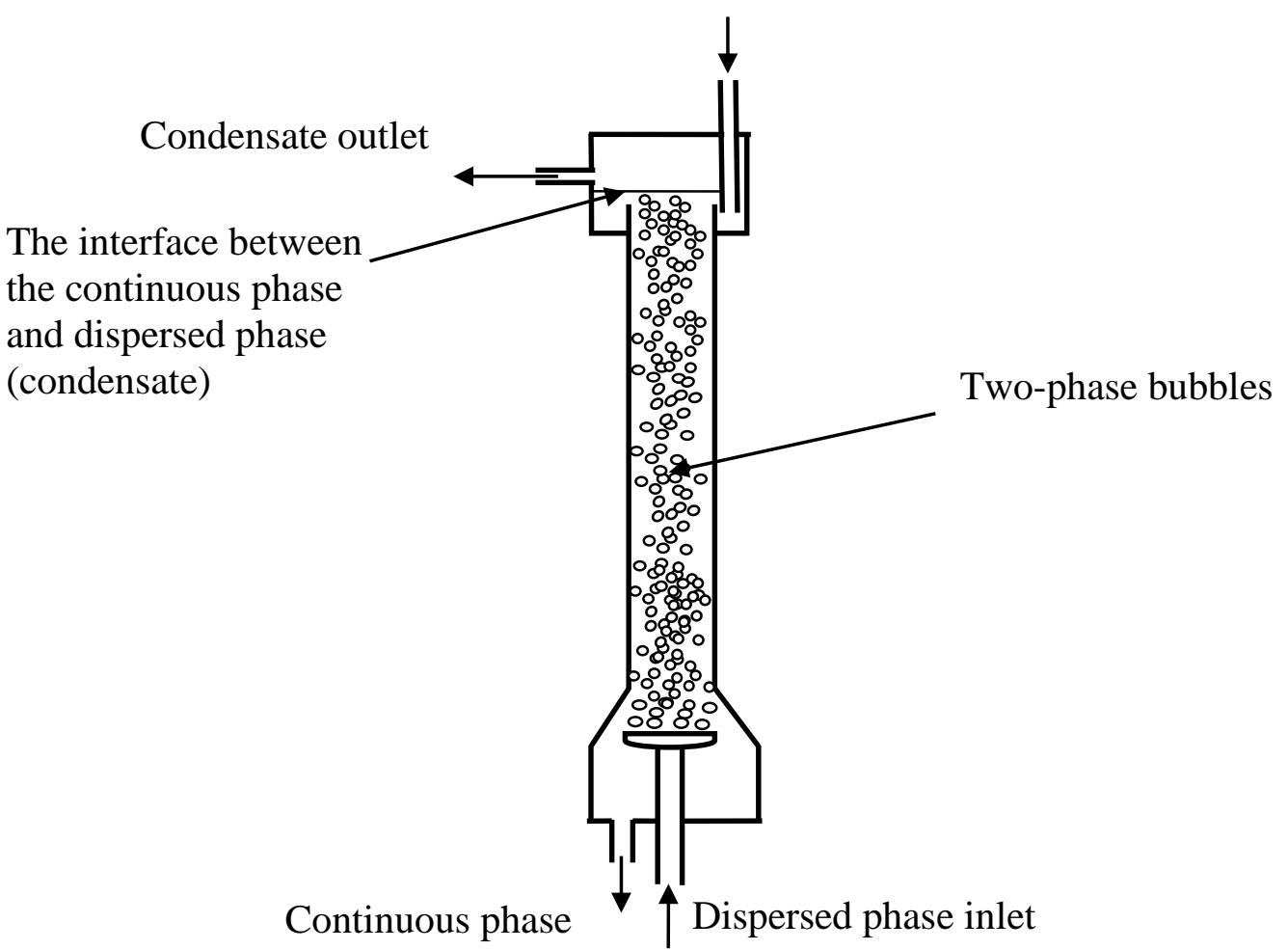

Fig. 2. Schematic diagram of the bubble type three-phase direct contact condenser.

The continuing enhancement of energy recovery cycles that exploit low grade energy resources requires an efficient heat absorption and rejection system. Implementation of a conventional surface type heat exchanger, evaporator or condenser has many disadvantages. The low efficiency, fouling, corrosion problems, high cost and high heat transfer resistance are the most important shortcomings that emerge as a result of the metallic barriers involved. On the other hand, a direct contact heat transfer device offers a high heat transfer area and reduces or eliminates fouling and corrosion problems. They can also work with very low temperature differences and subsequently can enhance the cycle efficiency. Direct contact heat exchangers clearly have many advantages over surface type heat exchangers and can also be efficiently used in places where the surface heat exchanger cannot be. Nevertheless, the main obstacles still facing the direct contact heat exchanger are: (i) the two-phases must be completely immiscible, and (ii) there is a lack of sufficient experimental data or theoretical design formulae available. However, in spite of the considerable literature available concerning the three-phase direct contact evaporator, there has been almost no attention been 
120 paid to the three-phase direct contact condenser. Although extensive investigations have 121 focused on the phenomenon of a single two-phase bubble [10-18] and bubble swarm [19-22] condensing in another immiscible liquid, which represents the base that the three-phase direct contact condenser can build on. Only the work of Sideman and Moalem [23] has been found

124 to be directly relevant to a three-phase direct contact condenser. They developed a 125 mathematical model to describe the direct contact condensation of a multi-train two-phase 126 bubble in another immiscible liquid. Although this study is not representative of a real three127 phase direct contact condenser, it has improved the general understanding of the condensation of a swarm of two phase bubbles in an immiscible liquid.

129 Recently, Mahood and co-authors [9, 24-29] investigated theoretically and experimentally 130 [24-28] the various characteristics of thermal performance of the three-phase direct contact condenser. The thermal efficiency and the capital cost of the three-phase direct contact condenser have been recently researched [9]. Relatively high condenser efficiency (about $75 \%$ ) with a relatively low mass flow rate ratio (about 25\%) has achieved. The capital cost was found to be decreased with increasing of the dispersed phase mass flow rate. The steadystate and the transient temperatures distribution along the three-phase direct contact condenser have studied experimentally and theoretically [24, 25], respectively. The results showed for both cases that the mass flow rate ratio and the holdup fraction have a significant effect on the condenser outlet temperature. Also, the volumetric heat transfer coefficient in the condenser has studied experimentally for both steady-state and transient operation modes $[26,27]$, respectively. The results indicated that the volumetric heat transfer coefficient decrease upon moving up the condenser and with time with a positive effect of mass flow rate ratio.

143 As mentioned above, author et al. have extensively researched the heat transfer characteristics 144 of the three-phase direct contact condenser under different operational conditions. However, 145 the heat transfer during flooding and the flow limitation of the condenser have excluded. In 146 this paper, the heat transfer during flooding in the three-phase direct contact condenser is 147 studied experimentally. The flow limitation of both continuous and dispersed phases was 148 determined. No attention is directed towards the flooding phenomena themselves. The transient temperature distribution, phase maps identifying flooding conditions and the volumetric heat transfer coefficient associated with flooding are estimated. 


\subsection{Flooding Phenomena}

154 It is economical and practical for the bubble type direct contact condenser to be operated at a 155 maximum possible holdup ratio to increase the condenser performance. It is widely reported 156 that the column performance is well described by a volumetric heat transfer coefficient [6].

157 Practically, the volumetric heat transfer coefficient increases directly with increasing the 158 holdup ratio in the column [6, 29-31]. On the other hand, when the direct contact column 159 operates with a high holdup ratio, the probability of the undesirable flooding phenomenon is 160 increased. This hampers the direct contact column's performance.

161 Two mechanisms could lead to the inception of flooding in the three direct contact columns, 162 depending on the critical velocity of each individual phase. The critical velocity can be 163 defined as a maximum velocity that can be achieved by a given direct contact system and it is 164 a function of the bubble size, the flow rate and the physical properties of the phases. The first mechanism depends on the reduction in the dispersed phase (bubbles) upward velocity due to

166 the interactions within a swarm of two-phase bubbles. The two-phase bubbles move closer 167 together when the dispersed phase flow rate increases, which results in a further dispersed 168 phase slowing. Bubbles are swept down and drain out with the continuous phase from the 169 bottom of the column. Therefore, the danger from this form of flooding form is the increased 170 loss of the working fluid. The second scenario assumes that the continuous phase is swept 171 upwards because of a high dispersed phase flow rate. This occurs when the dispersed phase velocity passes the critical velocity. The result of this flooding type lies in a change of

173 geometry and makes the heat transfer relationships available invalid. Accordingly, flooding 174 can be defined as the case when the continuous phase is completely held up by the dispersed 175 phase or the dispersed phase is swept backward by the continuous phase.

176 In practice, flooding can be diagnosed by monitoring the pressure difference across the 177 column or the temperature of the column. Depending on the flooding type, the temperature at 178 the bottom or top of the column may increase due to the blocking of vapour flow by a high 179 continuous phase flow rate in first type, or as a result of holding up the continuous phase by a 180 high dispersed phase flow rate in the second.

181 It is necessary to avoid both flooding forms throughout the direct contact spray column 182 design. The first flooding type can be avoided for a given condenser cross-sectional area by 183 increasing the column height or by using more than one continuous phase inlet and outlet. 184 The second type of flooding is avoided by ensuring that the space between neighbouring 
bubbles is large enough to prevent them from touching each other. The suitable spacing was found to be at least twice the initial radius of a bubble [32].

187 Flooding is a very complex phenomenon and depends strongly on the physical properties of 188 the two phases, the column geometry, the configuration of the inlets and outlets of the two 189 phases, the column diameter and the two-phases' velocities. Therefore there is a significant 190 divergence in this case from the results for a system without phase change. The simple 191 empirical expressions are only useful as a guide and accurate chemical process equipment 192 design depends on relevant experimental data.

193 Although, flooding phenomenon has been widely investigated over a number of decades especially for isothermal (gas-liquid) system a considerable uncertainty regarding the mechanism responsible on the flooding inception still existing [33]. However, depending on tube geometry and fluids properties, three different mechanisms for flooding inception were suggested; droplet dynamics, film flow dynamics and wave dynamics [34]. Nevertheless, there is no unique correlation can be used to predict the flooding inception. For a wide variety of fluid pairs and for a vertical tube with small diameter, the correlation of Hewitt and Wallis [35] have widely used.

For the case of flooding of the three-phase direct contact heat exchanger and with absence of especial correlations, Wright [32] tested the three most cited approaches which have been developed for a system without phase change by [36-38]. A great conflict in the results of these correlations was found. A more relevant study is reported by Goodwin et al. [31], where the flooding limit (downward flooding) of a large diameter spray column direct contact evaporator was evaluated experimentally. The variation of the point of inception for flooding with the two-phase mass flow rate and the column pressure for the downward flooding type was investigated. They observed that the possibility of flooding decreases with increasing the dispersed phase mass flow rate and the column pressure for a constant mass flow rate ratio.

\section{Experimental Facility}

\section{$212 \quad 2.1$ Experimental Setup}

213 Figure 3a shows the experimental layout. The detail of experimental setup and procedure can 214 be found in the previous research [24, 25]. Briefly, the experimental rig consists of two main 215 loops. The first loop is for the dispersed phase, and it uses liquid pentane as a working fluid. 216 There is a pentane storage tank (10 L), a liquid pentane circulation pump, a control valve, non 217 return valve, a heating or vaporisation vessel, trace heater and connection tubes. The second 
218 loop is for the continuous phase; it consists of a large water storage tank, pump, flow meters

219 and connection pipes. In addition, a Perspex cylindrical column of $48 \mathrm{~cm}$ active height from

$22070 \mathrm{~cm}$ total height is used as a direct contact condenser (test section). Eight K- type, calibrated

221 thermocouples, connected to a PC via an eight channel data logger, were used to measure the

222 temperature along the test section, the vapour in the heating vessel and the vapour just before

223 injection in to the column.

224 The heating vessel is a pool boiler type $(100 \mathrm{~cm} \times 50 \mathrm{~cm})$ and contains a long $(6 \mathrm{~m}$ length and $2256 \mathrm{~mm}$ diameter) copper coil. The heating vessel is completely full with water, which is used 226 as a media for heating up and vaporising liquid pentane. It is heated by two electric heaters (3

$227 \mathrm{~kW}$ each). The heating power is controlled by a thermostat through a control panel. One end 228 of the copper coil is connected to the liquid pentane storage tank via the liquid pentane 229 circulation pump and the flow rate is controlled by a ball valve. The non return valve is 230 installed at the inlet of the heating vessel to prevent dispersed phase back flow caused by the 231 heating vessel pressure head, especially during the shutdown period (pentane in liquid state) 232 when the injection valve is closed. The second end of the coil is connected to the test column 233 (direct contact condenser) by a short externally heated tube. The vapour (dispersed phase) 234 injection temperature and pressure were measured using a thermocouple and pressure gauge 235 respectively. The short injection tube is heated by a variable temperature trace heater.

\subsection{Experimental Procedure}

238 The experiment began by preparing the continuous phase (water) in its large size storage tank 239 (160 L volume) and maintaining its temperature at a desirable value $\left(19^{\circ} \mathrm{C}\right)$. The large storage 240 tank made the water temperature approximately invariant during each run (about 3 minutes).

241 The cooling water (continuous phase) was re circulated through the test section to maintain its 242 temperature. The water flow rate and the water level $(48 \mathrm{~cm})$ in the direct contact column (test 243 section) were determined and controlled by adjusting the two flow meters (one for water inlet 244 and second for water outlet)

245 The heating vessel was gradually warmed up by adjusting the power of electric heaters, until 246 the temperature reached the desired level. The liquid pentane (dispersed phase) was then 247 pumped to the heating vessel, where it warmed and evaporated (pentane boils at $36.5^{\circ} \mathrm{C}$ ) and 248 was then injected via the injection tube in to the test section (direct contact condenser). Its 249 temperature and pressure were measured before injection. Because of the trace heater, the 250 injection temperature of the dispersed phase was maintained constant during each run. The 
251 desired injection dispersed flow rate was specified and controlled by a calibrated ball valve in 252 a similar technique to that used by [24, 25, 39-41].

253 At the moment of vapour injection in to the test section, the temperature along the test 254 section is measured using five calibrated K-type thermocouples, fixed at different positions 255 from the bottom of the column (see Fig. 3b): TC1@0 cm (for continuous phase outlet), 256 TC2@12 cm, TC3@24 cm, TC4@36 cm and TC5@48 cm (for continuous phase inlet). 257 Three more thermocouples were used: one for measuring the condensate temperature at a 258 height of $52 \mathrm{~cm}$ and the other two are for the injected vapour temperature and for the 259 dispersed phase temperature in the heating vessel. All these thermocouples were connected to 260 an eight channel data logger to display the measured temperature directly on a PC.

261 The condensate was collected, weighted and divided by the duration of the experiment to 262 determine the dispersed phase mass flow rate. A conical separator was used to recover nearly 263 all the pentane from the drained water. The pentane collected as a condensate during each run 264 was directly sent back to the liquid pentane storage tank to use in a continuous run or to be 265 stored and used in another run.

266 The uncertainty of the thermocouples and the continuous phase mass flow rate measurement 267 are given in tables 1 and 2. For the dispersed phase mass flow rate measurement, the mass 268 balance after each run was used. The total error in the measurements, which consists of the 269 error in the digital scale, the loss of condensate due to the miscibility of pentane in water 270 (which is very small), the time of the run and the possibility of draining the condensate with 271 the continuous phase has also been calculated. The inaccuracy of the dispersed phase mass 272 flow rate is estimated to be $\pm 11 \%$. 


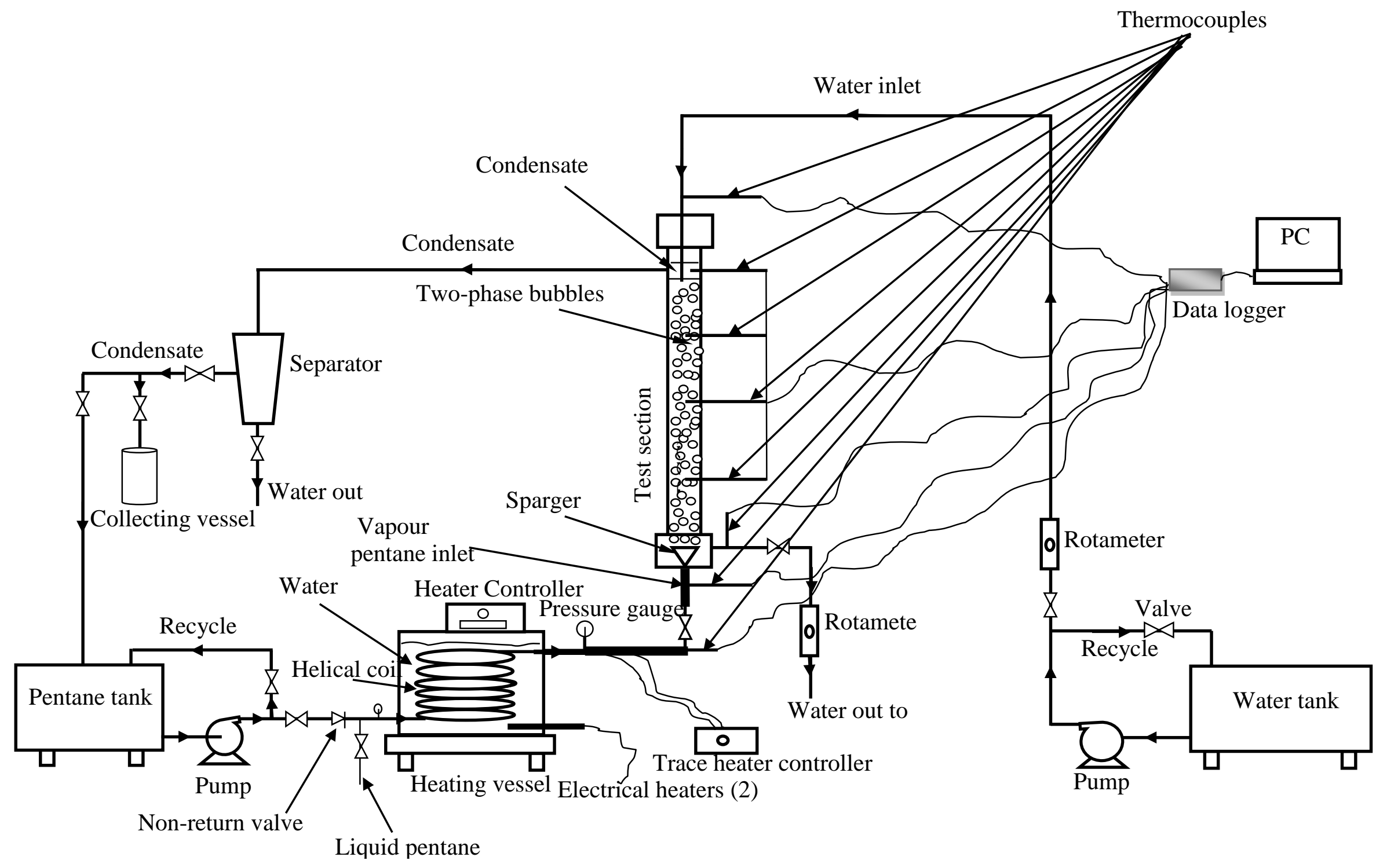

Fig. 3a . Schematic diagram of the experimental rig. 


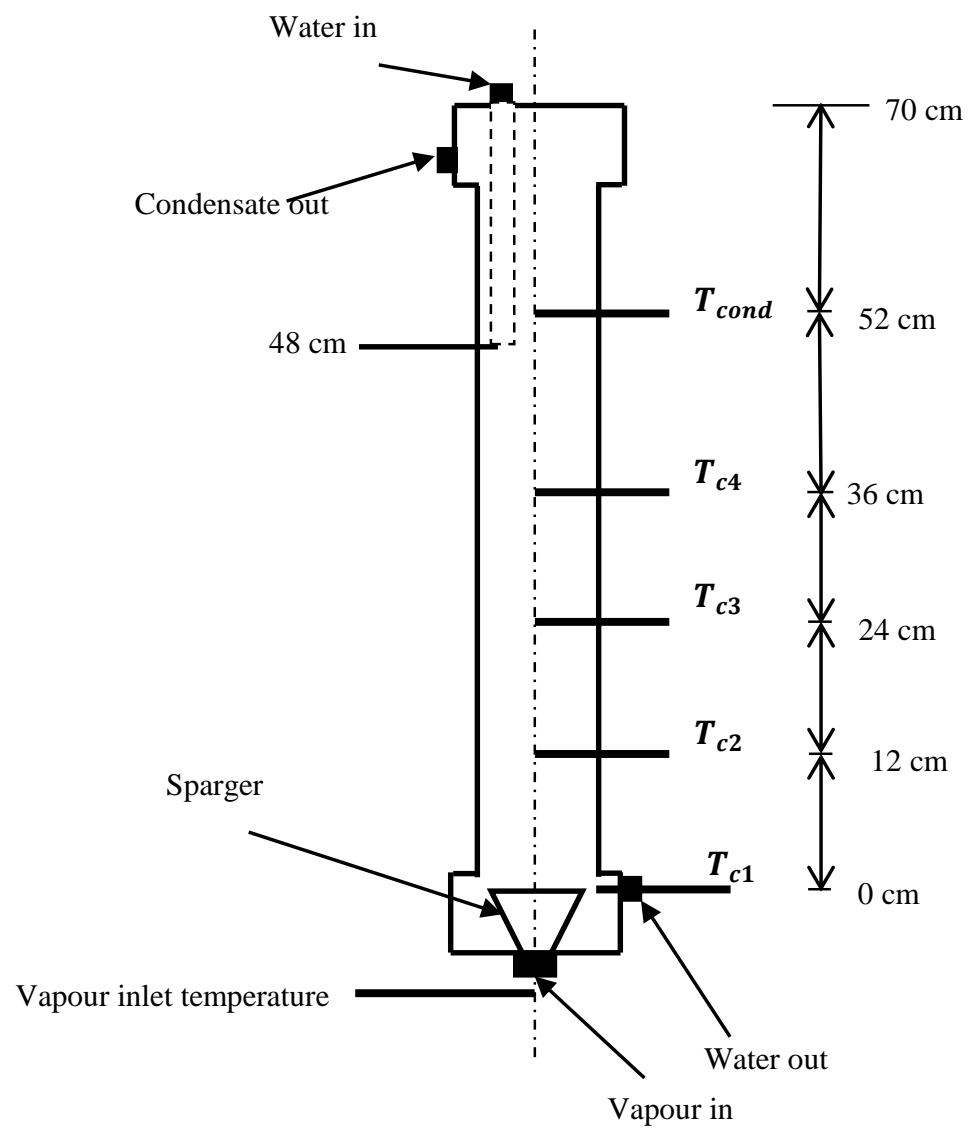

Fig. 3b. Thermocouple locations along the direct contact condenser column.

Table 1 Inaccuracy of the thermocouples

\begin{tabular}{|c|c|}
\hline $\mathbf{T}\left({ }^{\circ} \mathrm{C}\right)$ & Inaccuracy $\%$ \\
\hline $\boldsymbol{T}_{c \mathbf{1}}$ & \pm 0.440 \\
\hline $\boldsymbol{T}_{c \mathbf{2}}$ & \pm 0.508 \\
\hline $\boldsymbol{T}_{c \mathbf{3}}$ & \pm 0.325 \\
\hline $\boldsymbol{T}_{c \mathbf{4}}$ & \pm 0.359 \\
\hline $\boldsymbol{T}_{\boldsymbol{c o n d}}$ & \pm 0.582 \\
\hline $\boldsymbol{T}_{\boldsymbol{d i}}$ & \pm 0.480 \\
\hline $\boldsymbol{T}_{\boldsymbol{c i}}$ & \pm 0.353 \\
\hline
\end{tabular}




\begin{tabular}{|c|c|}
\hline$\dot{m}_{c}(\mathrm{~kg} / \mathrm{min})$ & $\begin{array}{l}\text { Rotameter inaccuracy } \\
\%\end{array}$ \\
\hline 0.0564 & \pm 6.000 \\
\hline 0.107 & \pm 10.608 \\
\hline 0.201 & \pm 8.636 \\
\hline 0.286 & \pm 4.666 \\
\hline 0.381 & \pm 4.750 \\
\hline
\end{tabular}

\section{Results and Discussion}

\subsection{Transient temperature distribution}

24 The present investigation is concerned with the heat transfer characteristics of a three-phase 25 direct contact condenser under flooding conditions. The mechanism and the factors affecting the inception of flooding of the three-phase direct contact condenser is outside the scope of the present study.

28 The experimental time dependent temperature distributions after and during the flooding 29 conditions are shown in Figures (4-6). It is clear that the temperature distribution along the 30 direct contact condenser during the flooding becomes more uniform as a result of an almost 31 completely mixed column. The cooling water is halted by the upward force produced by a 32 high vapour (dispersed phase) mass flow rate. Therefore, a static water column above the 33 dispersed phase injection is formed. Consequently, the cooling rate which is achieved by the 34 flowing continuous phase is reduced.

35 Visually, the inception of flooding is preceded by a transition from large spherical to 36 spherical cap bubbles which then developed to a long slug. The small column diameter, of 37 course, helps to create the long slug when the flooding limit is reached. As shown in the 38 figures (Figs. (4-6), the inception of flooding strongly depends on the mass flow rate of both 39 phases. Clearly, at a constant continuous phase mass flow rate, a higher dispersed phase mass 
flow rate results in an earlier inception of flooding (see sub-figures a \& b in Figs. (4-6)). This can be attributed to the larger upward force produced by the higher momentum of vapour. This causes the continuous phase to be suspended and then pushed up. In addition, the high dispersed phase flow produces large bubbles which help to accelerate the inception of flooding. Visual observation indicated that a vapour pocket emerged just above the sparger as a result of coalescence of the large non-uniform bubbles that were produced by a high dispersed phase mass flow rate. This structure broke down to large bubbles or sometimes slugs depending on the force produced by the continuous phase. However, coming back to Figs. (4-6), it is obvious that, for example, at $\dot{m}_{c}=0.0564 \mathrm{~kg} / \mathrm{min}$ and $T_{d i}=40^{\circ} \mathrm{C}$, the inception of flooding occurred after about 150s and 90s, from the beginning of runs with a continuous mass flow rate of $0.04035 \mathrm{~kg} / \mathrm{min}$ and $0.04872 \mathrm{~kg} / \mathrm{min}$ respectively. This is completely consistent with results for other initial temperatures and continuous mass flow rates. For example, the inception of flooding was observed after $170 \mathrm{~s}$ and 150s, for a continuous mass flow rate $0.039 \mathrm{~kg} / \mathrm{min}$ and $0.0472 \mathrm{~kg} / \mathrm{min}$ respectively $\left(T_{d i}=43.5^{\circ} \mathrm{C}\right)$. Finally, for $T_{d i}=47.5^{\circ} \mathrm{C}$, and continuous mass flow rates 0.0408 and $0.054 \mathrm{~kg} / \mathrm{min}$ the inception of flooding was seen after $155 \mathrm{~s}$ and $110 \mathrm{~s}$. The same behaviour was found for another continuous phase mass flow rate $\left(\dot{m}_{c}=0.107 \mathrm{~kg} / \mathrm{min}\right)$.

The temperature of the continuous phase along the column increased with time and a more rapid rise was seen over the first 50s, as observed by Mahood et al. [25]. This behaviour was also noticed during the experiments with flooding. After the onset of flooding, the thermocouples registered nearly the same temperature (see Fig. (4-6), after flooding inception point), with a notable decrease in the continuous phase outlet temperature (Tc1) also observed. This is because at flooding, the continuous phase liquid is stopped to reaching the bottom of the column, which leads to heat up the semi static water (continuous phase) column. Therefore, the injected dispersed phase (vapour) would not undergo a convective condensation and the dispersed phase would be almost vapour when is reached the top of the column, and a further condensation would take place by a relatively cooled continuous phase. This simply means, that at flooding the direct contact condensation will take place at the top of the column rather than at the bottom. Nevertheless, the temperature of the continuous phase seemed to be uniform for the case of complete flooding (after a while from inception of flooding), where the temperature of the continuous phase column had nearly the same temperature (see Figs. (4-6), after the inception of flooding). 
72 No considerable effect of initial dispersed phase temperature on the inception of flooding is 73 shown by the results (Figs. (4-6)). This consists with that the direct contact condensation is a 74 latent heat dominant [24-26, 42].

75 Schematically Figs. (7-9) show the maps of the mass flow rates of two phases (which result 76 in flooding) for three different dispersed initial temperatures. Again a high continuous mass 77 flow rate is clearly requires a high dispersed phase flow for a flooding to occur.

78 Figure 10 shows the relationship between the dispersed phase mass flow rate and the 79 continuous phase mass flow rate for a different initial dispersed phase temperatures, at the onset of flooding. Except at a high continuous mass flow rate (nearly $0.38116 \mathrm{~kg} / \mathrm{min}$ ), the initial temperature of the dispersed phase seems to have very little effect on the occurrence

82 of flooding within the temperature range of the present experiments.

83 As shown in Figures (4-6), the temperature distribution during flooding tends to be more 84 uniform with time due to the mixing along the column. This, of course, will change the heat 85 transfer rate in the column and subsequently change the column performance indicator, i.e. 86 volumetric heat transfer coefficient. The volumetric heat transfer coefficient, however, 87 increases with holdup towards the flooding limit [31]. 


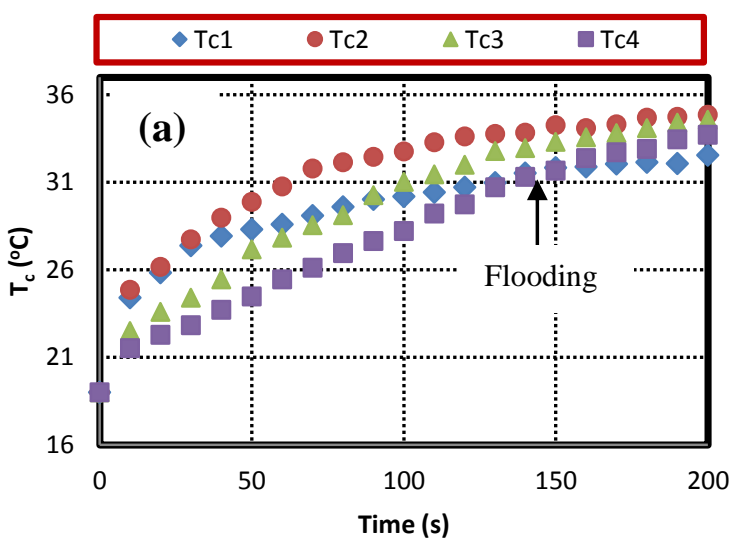

95

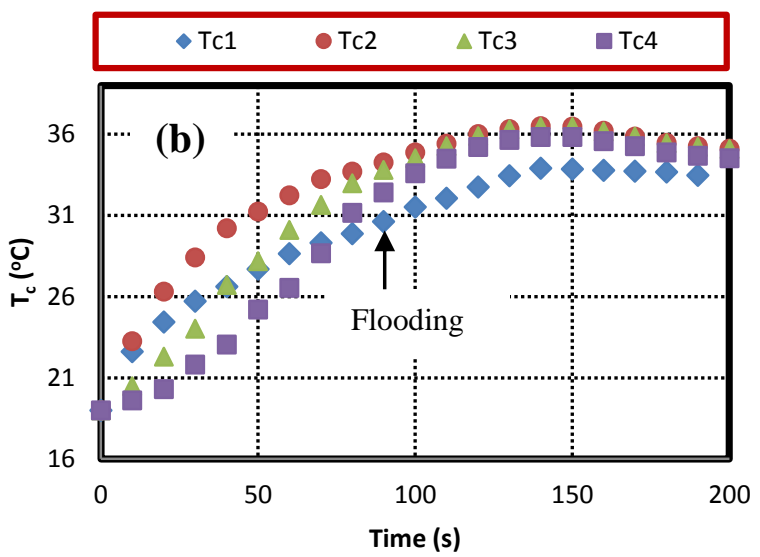

96

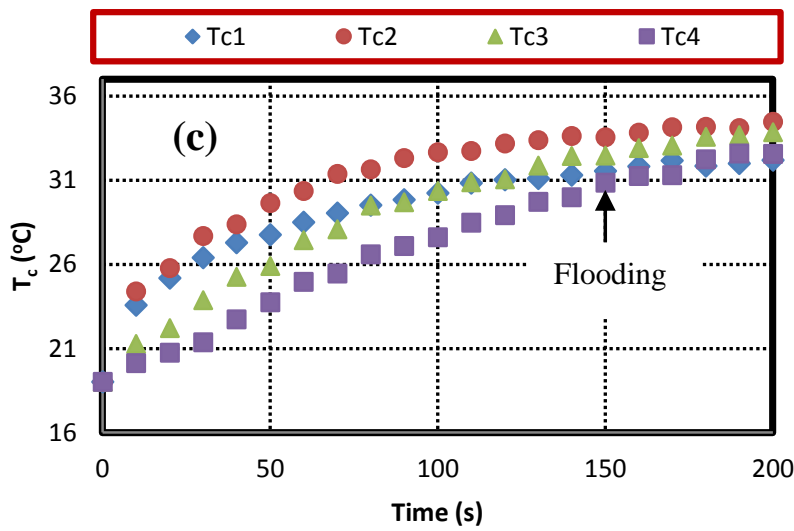

97

98 Fig. 4. Transient temperature distribution at, and during, DCC flooding for $\left(T_{d i}=40^{\circ} \mathrm{C}\right)$ and 99 (a): $\dot{m}_{c}=0.0564 \mathrm{~kg} / \min \& \dot{m}_{d}=0.04035 \mathrm{~kg} / \mathrm{min},(\mathbf{b}): \dot{m}_{c}=0.0564 \mathrm{~kg} / \mathrm{min} \& \dot{m}_{d}=$ $100 \quad 0.04872 \mathrm{~kg} / \mathrm{min}$ and $(\mathbf{c}): \dot{m}_{c}=0.107 \mathrm{~kg} / \mathrm{min} \& \dot{m}_{d}=0.0571 \mathrm{~kg} / \mathrm{min}$ 


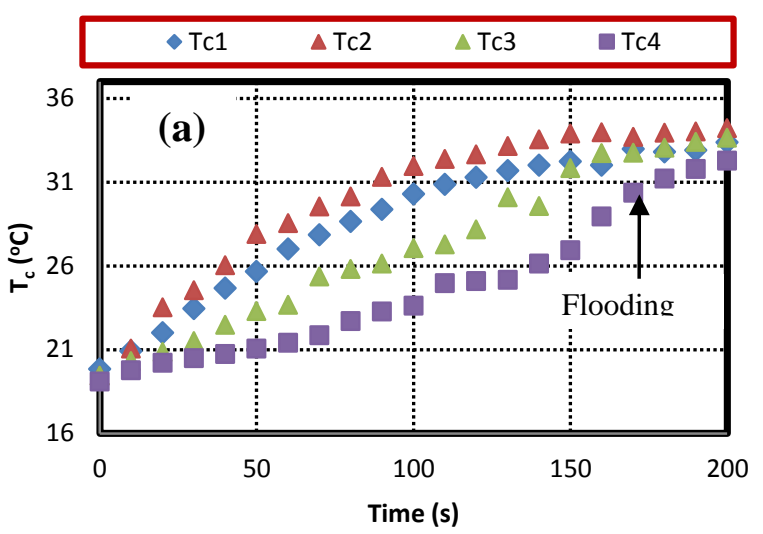

102

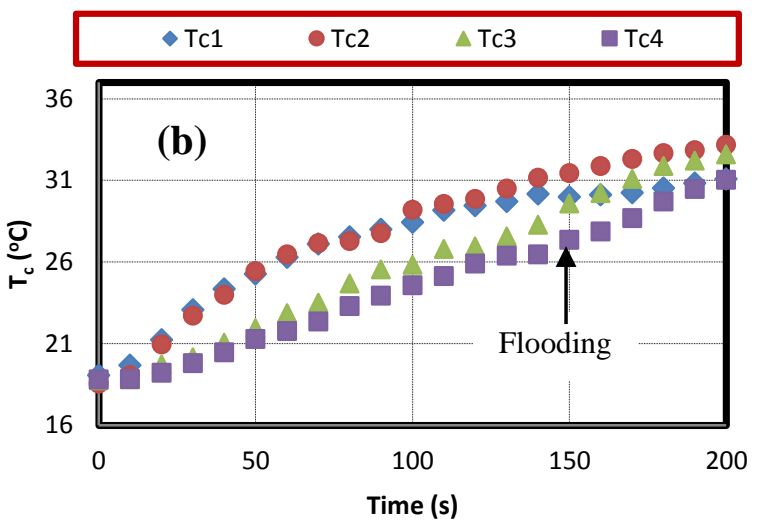

103

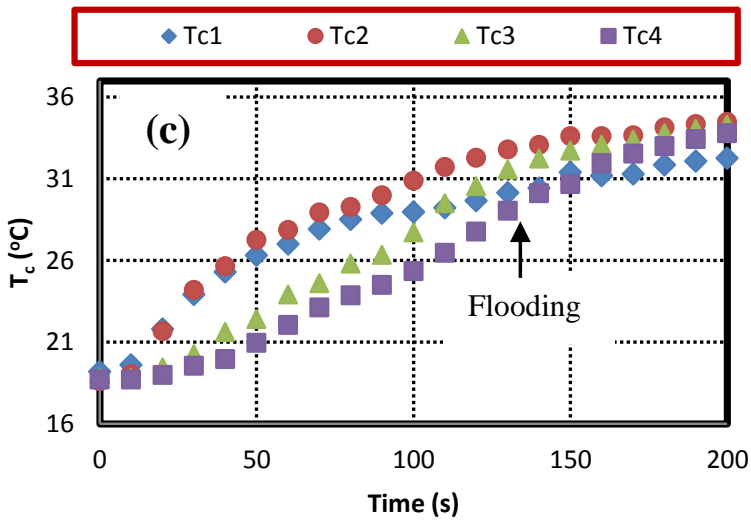

104

Fig. 5. Transient temperature distribution at, and during, DCC flooding for $\left(T_{d i}=40^{\circ} \mathrm{C}\right)$ and (a): $\dot{m}_{c}=0.0564 \mathrm{~kg} / \mathrm{min} \& \dot{m}_{d}=0.039 \mathrm{~kg} / \mathrm{min},(\mathbf{b}): \dot{m}_{c}=0.0564 \mathrm{~kg} / \mathrm{min} \& \dot{m}_{d}=$ 


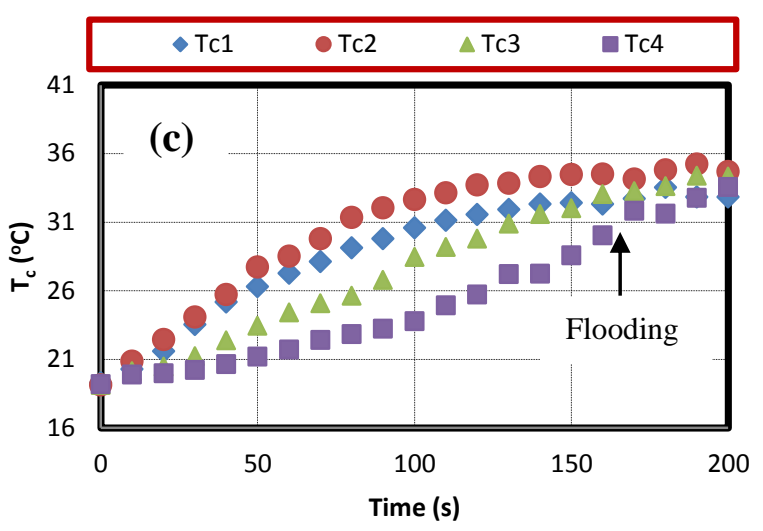

110

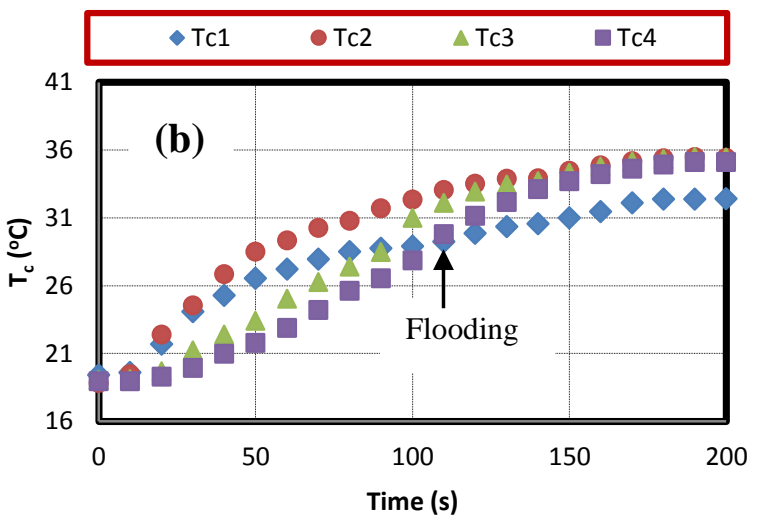

111

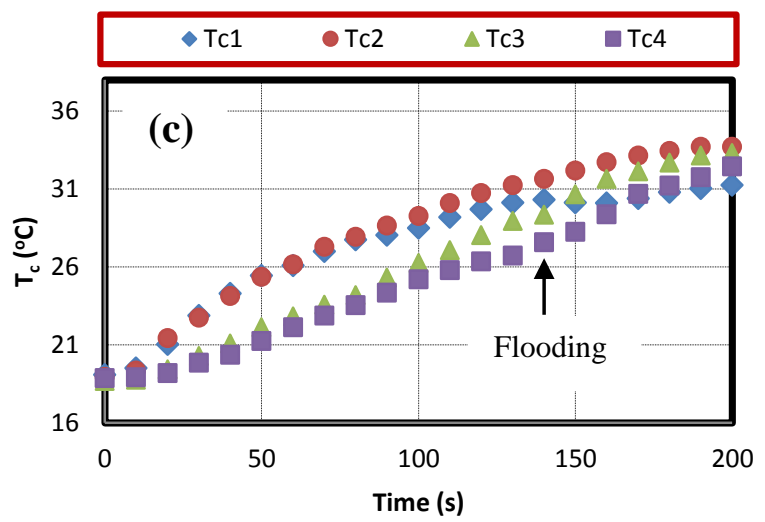

112

113 Fig. 6. Transient temperature distribution at, and during, DCC flooding for $\left(T_{d i}=40^{\circ} \mathrm{C}\right)$ and 114 (a): $\dot{m}_{c}=0.0564 \mathrm{~kg} / \mathrm{min} \& \dot{m}_{d}=0.0408 \mathrm{~kg} / \mathrm{min},(\mathbf{b}): \dot{m}_{c}=0.0564 \mathrm{~kg} / \mathrm{min} \& \dot{m}_{d}=$ $115 \quad 0.054 \mathrm{~kg} / \mathrm{min}$ and (c): $\dot{m}_{c}=0.107 \mathrm{~kg} / \mathrm{min} \& \dot{m}_{d}=0.046 \mathrm{~kg} / \mathrm{min}$ 


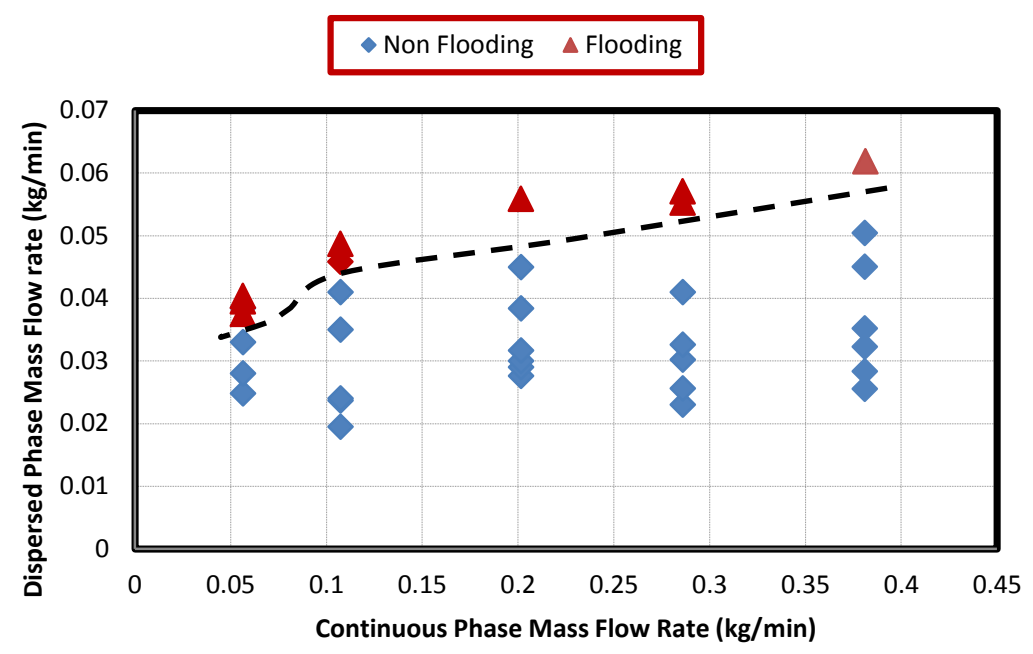

118

119 Fig. 7. Map of mass flow rates investigated showing flooding and non flooding cases $\left(T_{d i}=\right.$ 120 $\left.40^{\circ} \mathrm{C}\right)$

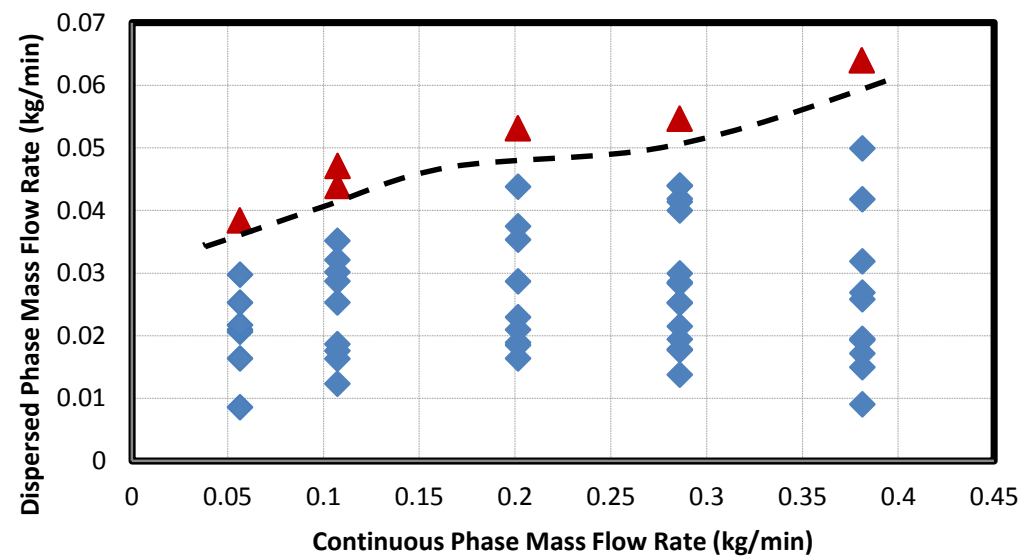

123 Fig. 8. Map of mass flow rates investigated showing flooding and non flooding cases $\left(T_{d i}=\right.$ 


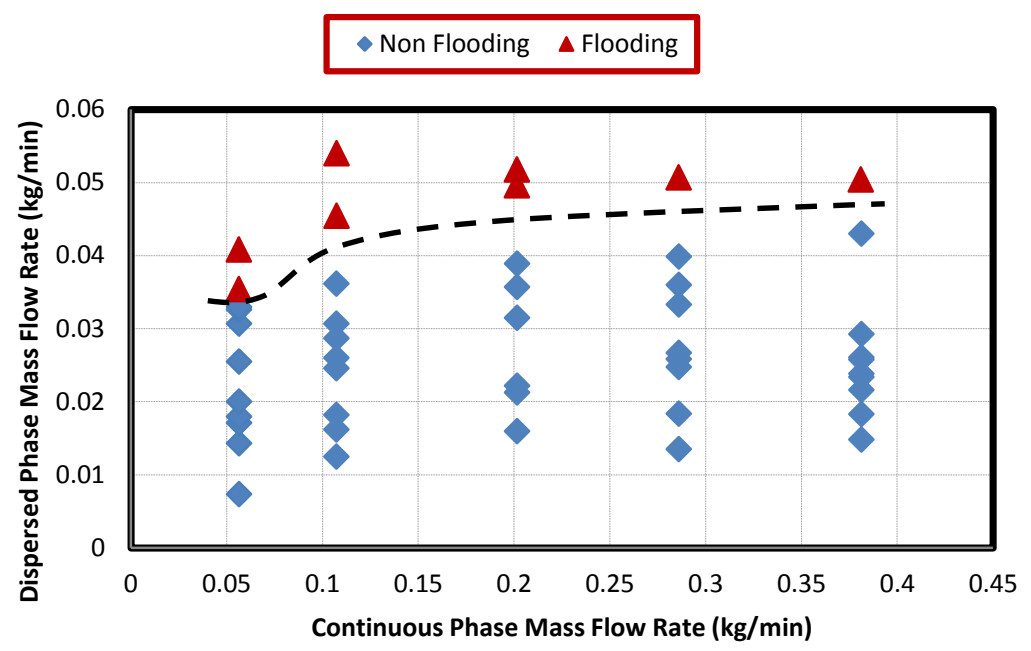

127 Fig. 9. Map of mass flow rates investigated showing flooding and non flooding cases $\left(T_{d}=\right.$

Tdi $=47.5$ oC $\quad T d i=43.5$ oC $\triangle \mathrm{Tdi}=40$ oC

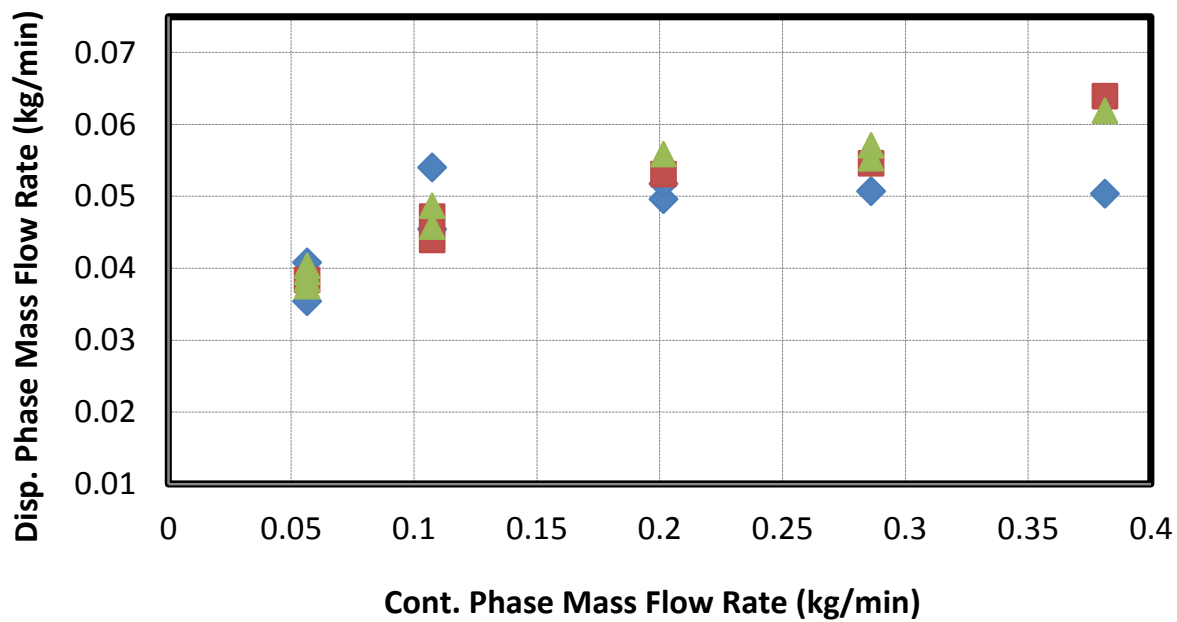

131 Fig. 10. Effect of the initial temperature of the dispersed phase on flooding inception 


\subsection{Volumetric heat transfer coefficient prediction}

138 To calculate the volumetric heat transfer coefficient of the three-phase direct contact 139 condenser, the column height was divided into four equal sub-volumes. An energy balance 140 over each individual sub-volume was performed based on the following assumptions:

$Q_{i}=\dot{m}_{c} C_{p c}\left(T_{c o}-T_{c i}\right)_{i}=\dot{m}_{d i} h_{f g}$

153 And the volumetric heat transfer coefficient is obtained as:

$154 \quad U_{v i}=\frac{Q_{i}}{A \Delta Z_{i}\left(\Delta T_{l m}\right)_{i}}$

where $\left(\Delta T_{l m}\right)_{i}, Q_{i}, A, \dot{m}_{c}, \dot{m}_{d i}$ and $\Delta Z_{i}$ denote the log-mean temperature difference for each sub-volume, the total heat transfer rate for each sub-volume, the direct contact condenser cross-sectional area, the continuous phase mass flow rate, the dispersed mass flow rate that condenses at sub-volume and the height of a sub-volume, respectively.

159 Accurate prediction of $U_{v i}$ through the direct contact heat exchange process requires an accurate knowledge of the temperate profile and consequently the temperature driving force.

161 This quantity, however, has a nonlinear distribution due to the backmixing and non-uniform 
162 two-phase bubble size and distribution within the column. This can be solved by using the

163 log-mean temperature difference. The log-mean temperature difference for our case may be

164 written as:

$165 \quad \Delta T_{l m}=\frac{\left(T_{c o}-T_{c i}\right)}{\ln \left(\frac{T_{d i}-T_{c i}}{T_{d i}-T_{c o}}\right)}$

166 Combining Eqs. (1-3) yields the volumetric heat transfer coefficient:

$167 \quad U_{v i}=\frac{\dot{m}_{c} C_{p c}}{A \cdot \Delta Z_{i}} \ln \left[\frac{\left(T_{d i}-T_{c o}\right)_{i}+\left(\frac{\dot{m}_{d i}}{\dot{m}_{c}}\right) \frac{h_{f g}}{C_{p c}}}{\left(T_{d i}-T_{c o}\right)_{i}}\right]$

168 where $C_{p c}, T_{d i}, T_{c o}$ and $h_{f g}$ denote specific heat of the continuous phase, the temperature of 169 the continuous phase at each individual sub-volume outlet, the temperature of the dispersed 170 phase at each individual inlet sub-volume and the latent heat of condensation, respectively.

171 Among those quantities, both the dispersed phase mass flow rate at each sub-volume and the 172 sub-volume dispersed phase inlet temperature, have to be estimated. The former can be 173 calculated using following expression:

$174 \quad \dot{m}_{d i}=\frac{Q_{i}}{h_{f g}}$

where $Q_{i}$ denotes the heat transfer rate at each sub-volume.

176 The dispersed phase inlet temperature of each sub-volume can be predicted using Antoine 177 equation.

178 Figures 11 to 13 show the variation of the volumetric heat transfer coefficient for different 179 initial dispersed phase temperatures and different mass flow rate ratios. A constant 180 volumetric heat transfer coefficient along the direct contact column is clearly observed for the 181 cases with a high dispersed phase mass flow rate, where the column completely flooded. This 182 is regardless of how much the initial dispersed phase temperature or the continuous phase 183 mass flow rate change. Of course, higher continuous or dispersed phase mass flow rate leads 184 to a higher volumetric heat transfer coefficient, which is vividly shown by the figures.

185 As mentioned above, during flooding conditions, the temperature along the direct contact 186 column tends to be uniform and nearly constant. Rapid increase in the continuous phase 187 temperature along the direct contact condenser takes place as shown by the Figures (4-6). 
188 This, of course, affects the volumetric heat transfer along the column and makes it nearly constant. This invariance of the volumetric heat transfer coefficient becomes clearest when it

190 works under complete flooding conditions, as shown by Figures 11 to 13. This behaviour

191 diminishes and the volumetric heat transfer might go to zero when the continuous phase

192 completely stops flowing down, as indicated by Eq. (4). This is because of the continuous

193 mass flow rate goes to zero. Therefore, it is important to set the direct contact condenser

194 diameter at a point near to its flooding limit and adjusting the holdup ratio within the

195 condenser to achieve a maximum heat exchange. The maximum error in the volumetric heat transfer coefficient was calculated and found $\pm 1.15 \%$.

197

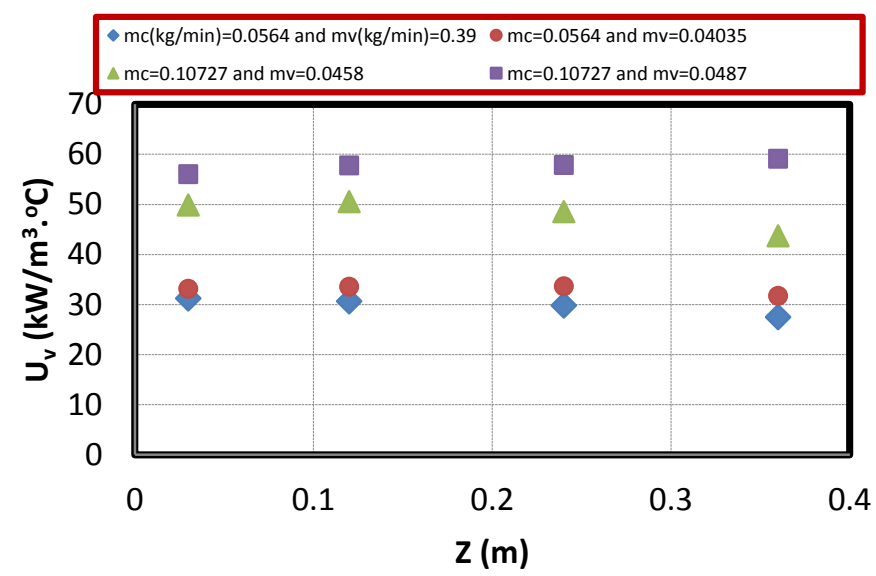

198

Fig. 11. Volumetric heat transfer coefficient of DCC during flooding inception for $\left(T_{d i}=\right.$ $40^{\circ} \mathrm{C}$ ) and four different continuous and dispersed phase mass flow rates

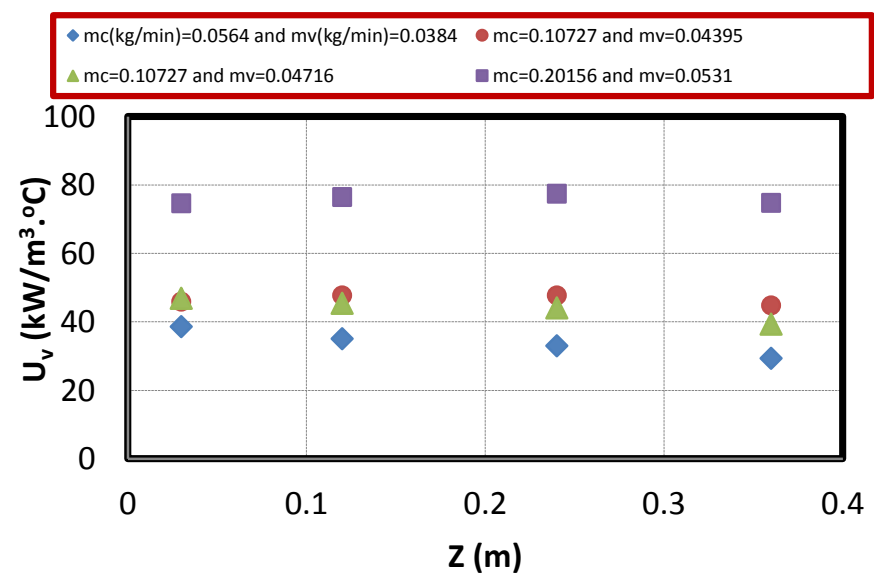

Fig. 12. Volumetric heat transfer coefficient of DCC during flooding inception for $\left(T_{d i}=\right.$ $43.5^{\circ} \mathrm{C}$ ) and four different continuous and dispersed phase mass flow rates 


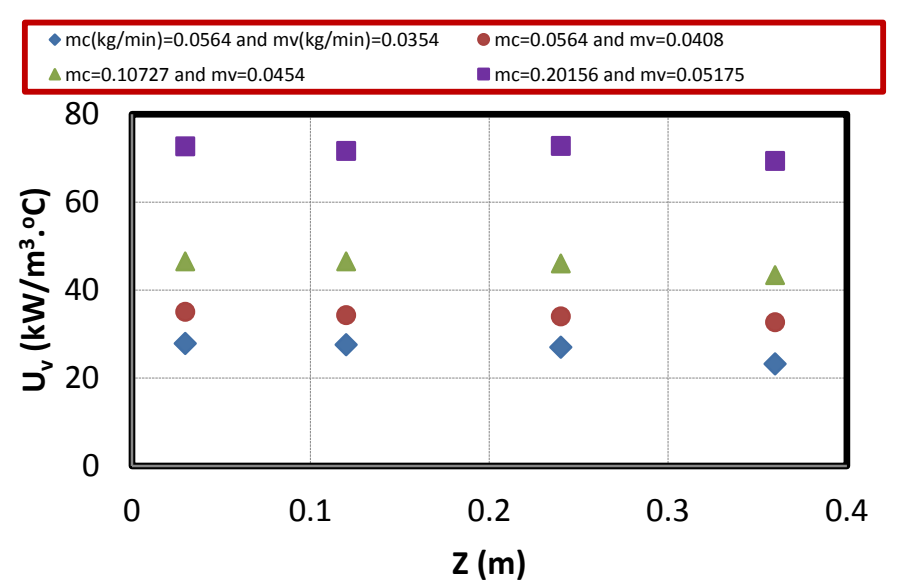

Fig.13. Volumetric heat transfer coefficient of DCC during flooding inception for $\left(T_{d i}=\right.$ $47.5^{\circ} \mathrm{C}$ ) and four different continuous and dispersed phase mass flow rates

\section{Conclusions}

209 It was reported that flooding is the main shortcoming that can hinder performance of the 210 three-phase spray column direct contact heat exchanger. In the present study, an experimental 211 investigation of the heat transfer during the inception of flooding in a three-phase direct

212 contact condenser was carried out.

213 Only the transient temperature distribution, the simple flooding map and the volumetric heat

214 transfer coefficient were considered. The detailed study of this undesirable phenomenon may 215 require a much more in-depth study. According to the data that was obtained, the time216 dependent temperature distribution tends to be homogenised along the column after the onset 217 of flooding. The visualisation study showed that flooding is preceded by the formation of 218 large spherical, spherical-cap and finally slug bubbles. In addition, the dispersed phase mass 219 flow rate required to create flooding is proportional to the continuous phase mass flow rate. 220 The volumetric heat transfer coefficient increases towards the flooding inception and then 221 decreases afterwards.

223 Nomenclatures

$224 \quad$ cross-sectional area of column, $m^{2}$

225 a radius of two-phase bubble, $m$ 
$226 C_{p c} \quad$ specific heat of continuous phase, $\mathrm{kJ} / \mathrm{kg} \cdot{ }^{\circ} \mathrm{C}$

227 DCC direct contact condenser

$228 \quad h_{f g} \quad$ latent heat of condensation, $\mathrm{kJ} / \mathrm{kg}$

$229 \quad \dot{m}_{d} \quad$ dispersed phase mass flow rate, $\mathrm{kg} / \mathrm{min}$

$230 \quad \dot{m}_{c} \quad$ continuous phase mass flow rate, $\mathrm{kg} / \mathrm{min}$

$231 \quad \dot{m}_{v} \quad$ dispersed (vapour) mass flow rate, $\mathrm{kg} / \mathrm{min}$

$232 \quad$ heat transfer rate, $k W$

$233 T$ temperature, ${ }^{\circ} \mathrm{C}$

$234 T c 1-4$ temperature of continuous phase at $\mathrm{f}$ different locations along column, ${ }^{\circ} \mathrm{C}$

$235 \Delta T_{l m} \quad$ log-mean temperature difference, ${ }^{\circ} \mathrm{C}$

$236 \mathrm{U} \quad$ velocity of continuous phase, $\mathrm{m} / \mathrm{s}$

$237 \quad V_{r} \quad$ radial velocity component, $\mathrm{m} / \mathrm{s}$

$238 V_{\theta} \quad$ tangential velocity component, $\mathrm{m} / \mathrm{s}$

$239 \Delta Z \quad$ sub-height along column, $m$

$240 \quad$ Greek symbol

$241 \quad \beta \quad$ half opening angle, degrees

242 Subscripts

243 c continuous phase

244 d dispersed phase

245 i initial, or location 


\section{References}

250 [1] K. Higeta, Y.H. Mori, K. Komotori, Condensation of a single vapor bubble rising in another immiscible liquid. AIChES ymp.75 (189) (1979), San Diego, 256-265.

252 [2] J. Isenberg, S. Sideman, Direct contact heat transfer with change of phase: bubble condensation in immiscible liquids. International Journal of Heat and Mass Transfer 13(1970) 997-1011.

255 [3] S. Sideman, G. Hirsch, Y. Gat, Direct contact heat transfer with change of phase: Effect 256 of the initial drop size in three-phase heat exchangers. AIChE Journal 11(6) (1965) 10812571087.

258 [4] S. Sideman, Y. Gat, Direct contact heat transfer with change of phase: Spray-column 259 studies of a three-phase heat exchanger. AIChE Journal 12(2) (1966) 296-303.

260 [5] J. Siqueiros, O. Bonilla, An experimental study of a three-phase, direct-contact heat exchanger. Applied Thermal Engineering 19(5) (1999) 477-493.

262 [6] Y.H. Mori, An analytic model of direct-contact heat transfer in spray-column evaporators. AIChE Journal, 37(4) (1991) 539-546.

264 [7] Z. Peng, W. Yiping, G. Cuili, W. Kun, Heat transfer in gas-liquid-liquid three-phase direct-contact exchanger. Chemical Engineering Journal 84(3) (2001) 381-388.

266 [8] H.R. Jacobs, H. Fannar, Direct contact condensers: a literature survey, USDOE Report, 267 DOE/1523-3, Department of Energy: Washington, D.C.(1977).

268 [9] H.B. Mahood, A.N. Campbell, R.B.Thorpe, A.O. Sharif, Heat transfer efficiency and 269 capital cost evaluation of a three-phase direct contact heat exchanger for the utilisation of 270 low-grade energy sources, Ene. Conv. Mang. 106 (2015) 101-109.

271 [10] Sideman S., and Hirsch G., Direct contact heat transfer with change of phase: 272 Condensation of single vapour bubbles in an immiscible liquid medium. Preliminary studies, 273 AIChE J. vol.11, no. 6, pp.1019-1025, 1965.

274 [11] J. Isenberg, S. Sideman, Direct contact heat transfer with change of phase: Bubble 275 condensation in immiscible liquids, Int. J. Heat Mass Transfer 13(1970) 997-1011. 
[12] D. Moalem, S. Sideman, The effect of motion on bubble collapse, Int. J. Heat Mass Transf. 16(1973) 2321-2329.

[13] H.R. Jacobs, B.M. Major, The effect of noncondensable gases on bubble condensation in an immiscible liquid, J. Heat Transf. 104(1982) 487-492.

[14] L. Lerner, H. Kalman, R. Letan , Condensation of an accelerating-decelerating bubble: experimental and phenomenological analysis, J. Heat Transf. 109 (1987) 509-517.

[15] Y. Lerner, R. Letan, Dynamics of condensing bubbles at intermediate frequencies of injection, J. Heat Transf. 112(1990) 825-829.

[16] R.K. Wanchoo, Forced convection heat transfer around large two-phase bubbles condensing in an immiscible liquid, Heat Recovery System\& CHP, 13(5) (1993) 441449.

[17] R.K. Wanchoo, S.K. Sharma, G.K. Raina, Drag coefficient and velocity of rise of a single collapsing two-phase bubbler, AIChE J. 43(8) (1997) 1955-1963.

[18] H. Kalman, Y.H. Mori, Experimental analysis of a single vapour bubble condensing in subcooled liquid, Chem. Eng. J. 85(2002) 197-206.

[19] D. Moalem, S. Sideman, A. Orell , G. Hetsroni, Direct contact heat transfer with change of phase: Condensation of a bubble train, Int. J. Heat Mass Transf. 16(1973) 2305-2319.

[20] H. Kalman, Condensation of a bubble train in immiscible liquids, Int. J. Heat Mass Transf. 49(2006) 2391-2395.

[21] H.B. Mahood, A.O. Sharif, S. Al-Aibi, R.B. Thorpe, Heat transfer modelling of two phase bubbles swarm condensing in three-phase direct-contact condenser, J. Therm. Sci. (2014) DOI: $\underline{\text { 10.2298/TSCI130219015M. }}$

[22] H.B. Mahood, A.N. Campbell, R.B. Thorpe, A.O. Sharif, A new model for the drag coefficient of a swarm of condensing vapour-liquid bubbles in a third immiscible liquid phase, Chem. Eng. Sci. 131(2015)76-83.

[23] S. Sideman, D. Moalem, Direct contact heat exchangers: Comparison of counter and cocurrent condensers, Int. J. Multiphase Flow 1(1974) 555-572. 
[24] H.B. Mahood, A.O. Sharif, S. Al-aibi, D. Hwakis, R.B. Thorpe, Analytical solution and experimental measurements for temperatures distribution prediction of three-phase direct contact condenser, J. Energy 67(2014) 538-547.

[25] H.B. Mahood, R.B. Thorpe, A.N. Campbell , A.O. Sharif, Experimental measurements and theoretical prediction for the transient characteristic of a three-phase direct contact Condenser, Submitted to the J. Appl. Them. Eng. 87(2015) 161-174.

[26] H.B. Mahood, A.N. Campbell, R.B. Thorpe, A.O. Sharif, Experimental measurements and theoretical prediction for the volumetric heat transfer coefficient of a three-phase direct contact condenser, Int. Comm. Heat Mass Trans. 66(2015)180-188.

[27] H.B. Mahood, A.O. Sharif, R.B. Thorpe, Transient volumetric heat transfer coefficient prediction of a three-phase direct contact condenser, J. Heat Mass Transf. 51(2) (2015) 165-170.

[28] G.L. Bauerle, R.C. Ahlert, Heat transfer and holdup phenomena in spray column. Industrial \& Engineering Chemistry Process Design and Development 4(2) (1965) 225-230.

[29] A. Markowitz, A.F. Bergles, Heat transfer in spray column.. AIChE Symp. Ser., 66(102) (1970) 63-71.

[30] P. Goodwin, M. Coban, R. Boehm, Evaluation of the flooding limits and heat transfer of a direct contact three phase spray column, National Heat Transfer Conference, Denver August, (1985) 1-5.

[31] J.D. Wright, Sizing of direct-contact preheater-boilers for solar-pond power plants, AC02-77CH00178: Solar Energy Research Inst., Golden CO.,Oak Ridge Tennessee, USA (1982).

[32] A.A. Mouza, M.N. Pantzali, S.V. Paras, Falling film and flooding phenomena in small diameter vertical tubes: the influence of liquid properties, Chem. Eng. Sci. 60(81)(2005) 4981-4991.

[33] Guo, Tiandong, Ji Hwan Jeong, Experimental study on flooding and flow reversal in small diameter tubes with various inclinations and horizontal lengths. Int. J. Refrigeration 38 (2014) 290-298.

[34] G.F. Hewitt, G.B. Wallis, Flooding and associated phenomena in falling film flow in a tube, REPORT AREA R-4022: UK Atomic Energy Agency, Harwell (1963). 
333

[35] J. Richardson, W. Zaki, Sedimentation and fluidization, Part I, Trans. Inst. Chem. Eng. 32(1954) 35-53.

[36] B. Sakiadis, A. Johnson, Generalized correlation of flooding rate, Ind. Eng. Chem. 46 (1954) 1229-1239.

[37] G. Minard, A. Johanson, Limiting flow and holdup in a spray extraction column, Chem. Eng. Prog. 48(1958) 62-74.

[38] V. Bontozoglou, A. Karabelas, Direct-contact stream condensation with simultaneous noncondensable gas absorption, AIChE J. 41(2) (1995) 241-250.

[39] C. Monning, R. Numrich, Condensation of vapours of immiscible liquids in the presence of a non-condensable gas, Int. J. Therm. Sci. 38(1999) 684-694.

[40] O. Seungmin, Sh. Revankar, Effect of noncondensable gas in a vertical tube condenser, Nucl. Eng. Desi. 235(2005) 1699-1712.

[41] H.B. Mahood, R.B. Thorpe, A.N. Campbell, A.O. Sharif, Effect of various parameters on the temperature measurements in a three-phase direct contact condenser, Int. J. Therm. Tech. 5(1) (2015) 23-27.

[42] H.B. Mahood, A.O. Sharif, S.A. Hossini, R.B. Thorpe, Analytical modelling of a spray column three-phase direct contact heat exchanger, ISRN Chemical Engineering, Article ID 457805(2013) http://dx.doi.org/10.1155/2013/457805.

[43] T. Coban, R. Boehm, Performance of a three-phase, spray -column, direct-contact heat exchanger, J. Heat Trans. 111(1) (1989) 166-172.

[44] H.R.Jacobs, M. Golafshani, Heuristic evaluation of the governing mode of heat transfer in a liquid-liquid spray column, J. Heat Trans. 111(3) (1989) 773-779. 